\title{
Article
}

\section{Self-assembling peptide nanofiber hydrogels for controlled ocular delivery of timolol maleate}

Christina Karavasili, Anastasia Komnenou, Orestis L. Katsamenis, Glykeria Charalampidou, Evangelia Kofidou, Dimitrios Andreadis, Sotirios Koutsopoulos, and Dimitrios G. Fatouros

ACS Biomater. Sci. Eng., Just Accepted Manuscript • DOI: 10.1021/acsbiomaterials.7b00706 • Publication Date (Web): 04 Nov 2017

Downloaded from http://pubs.acs.org on November 10, 2017

\section{Just Accepted}

"Just Accepted" manuscripts have been peer-reviewed and accepted for publication. They are posted online prior to technical editing, formatting for publication and author proofing. The American Chemical Society provides "Just Accepted" as a free service to the research community to expedite the dissemination of scientific material as soon as possible after acceptance. "Just Accepted" manuscripts appear in full in PDF format accompanied by an HTML abstract. "Just Accepted" manuscripts have been fully peer reviewed, but should not be considered the official version of record. They are accessible to all readers and citable by the Digital Object Identifier (DOI®). "Just Accepted" is an optional service offered to authors. Therefore, the "Just Accepted" Web site may not include all articles that will be published in the journal. After a manuscript is technically edited and formatted, it will be removed from the "Just Accepted" Web site and published as an ASAP article. Note that technical editing may introduce minor changes to the manuscript text and/or graphics which could affect content, and all legal disclaimers and ethical guidelines that apply to the journal pertain. ACS cannot be held responsible for errors or consequences arising from the use of information contained in these "Just Accepted" manuscripts. 


\title{
Self-assembling peptide nanofiber hydrogels for
}

\section{controlled ocular delivery of timolol maleate}

\author{
Christina Karavasili ${ }^{\#}$, Anastasia Komnenou ${ }^{ \pm}$, Orestis L. Katsamenis $^{\prime}$, Glykeria Charalampidou ${ }^{ \pm}$,

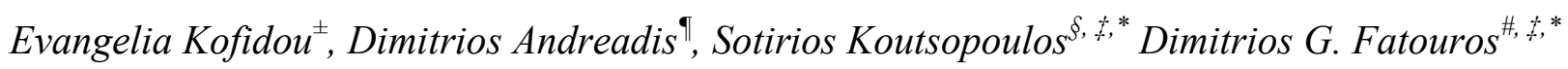

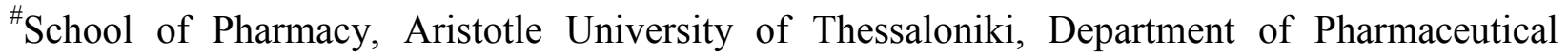 \\ Technology, GR-54124 Thessaloniki, Greece \\ ${ }^{ \pm}$Ophthalmology Unit, Companion Animal Medicine, School of Veterinary Medicine, Faculty of \\ Health Sciences, Aristotle University of Thessaloniki, Thessaloniki, Greece. \\ ' $\mu$-VIS X-ray Imaging Centre, Faculty of Engineering and the Environment, University of \\ Southampton, Southampton, SO17 1BJ, UK \\ IDepartment of Oral Medicine/Pathology, School of Dentistry, Aristotle University of \\ Thessaloniki, GR-54124 Thessaloniki, Greece \\ ${ }^{\S}$ Center for Biomedical Engineering, Massachusetts Institute of Technology, 77 Massachusetts \\ Avenue, Cambridge, MA 02139, USA \\ These authors contributed equally.
}




\begin{abstract}
The self-assembling peptides Ac-(RADA) $)_{4}-\mathrm{CONH}_{2}$ and Ac-(IEIK) $)_{3} \mathrm{I}-\mathrm{CONH}_{2}$ which form hydrogels in physiological conditions were evaluated as carriers for ocular delivery of the $\beta$ blocker timolol maleate. Electron microscopy studies revealed that hydrogels contain nanofibers, whereas rheological studies showed that the Ac-(IEIK) $)_{3} \mathrm{I}-\mathrm{CONH}_{2}$ self-assembles in a stiffer hydrogel compared with the Ac-(RADA) $)_{4}-\mathrm{CONH}_{2}$ peptide. The in vitro release and ex vivo permeation studies demonstrated controlled release and transport of the drug through the cornea, which depended on the self-assembling peptide sequence. In vivo studies in rabbits showed significant increase in the area under the concentration-time curve (AUC) after administration of the drug for the Ac-(RADA) $)_{4}-\mathrm{CONH}_{2}$ hydrogel compared to drug solution, whereas a sustained reduction of intraocular pressure for up to $24 \mathrm{~h}$ after instillation was achieved for both drug loaded hydrogels. Histological studies revealed good ocular tolerability upon application of the formulations, suggesting that self-assembling peptide hydrogels are promising systems for sustained ocular drug delivery.
\end{abstract}

KEYWORDS: self-assembling peptide, ocular delivery, timolol maleate, glaucoma, intraocular pressure, pharmacokinetics 


\section{INTRODUCTION}

The unique anatomy and structure of the eye remains a formidable challenge for the ocular delivery of drug molecules. More than $90 \%$ of the marketed ophthalmic formulations are in the form of eye drops. ${ }^{1}$ Conventional eye-drops are commonly applied in doses of $40 \mu \mathrm{L}$ which are subsequently replenished to an average resident tear volume of $7 \mu \mathrm{L}^{2}$ Eye drops that are used for the treatment of ocular diseases are applied frequently because the active compound is cleared rapidly from the eye. This results to low bioavailability in the aqueous humor ranging between 1 - $5 \%$, which is associated with high systemic exposure and potential off-target toxic effects. ${ }^{2,3}$ The cornea is the primary route of anterior drug delivery for the treatment of diseases like glaucoma, dry eye, keratitis and other pathological conditions. Therefore, significant effort in conventional formulations is directed towards increasing the pre-corneal retention time and corneal permeability. ${ }^{4}$

The in situ formation of a drug delivery carrier encapsulating the pharmacological agent in the cul-de-sac of the eye represents an ideal method to address these challenges. Stimuli responsive biomaterials, such as hydrogels undergoing sol-gel transition in response to changes in temperature, $\mathrm{pH}$ or ionic strength have been suggested as suitable carriers for ocular drug delivery because they can significantly enhance the residence time and slow down nasolacrimal drainage. ${ }^{5}$. Examples of polymers tested for ocular drug delivery applications include cellulose acetate phthalate, which gels in response to $\mathrm{pH}^{6}$ and poloxamer, which gels in response to temperature. $^{7,8}$ Slow-release, hydrogel-based formulations containing the $\beta$-blocker timolol maleate for glaucoma therapy have reached the market branded as Timoptic ${ }^{\circledR}$ XE, which contains gellan gum and as Geltim ${ }^{\circledR}$, which contains polyvinyl alcohol and carbomers. These aqueous polymer solutions gel upon interacting with tears and show reduced vision-blurring problems, 
contrary to the use of other ointments. ${ }^{9}$ Recently, electrohydrodynamic atomization was employed for ocular drug delivery applications through fiber coating of contact lenses, showing the potential of the platform in reducing drug drainage and increasing drug transport across the cornea. $^{10-13}$

Self-assembling peptide hydrogels constitute a class of bio-inspired materials, which have been tested in a plethora of biomedical applications, including tissue engineering and regenerative medicine ${ }^{14-16}$ and controlled drug release. ${ }^{17-21}$ These peptides have a hydrophobic side and a hydrophilic side which contains alternating positively and negatively charged residues. Upon addition of an electrolyte solution, the self-assembling process is initiated by intra- and interassociation of adjacent peptides, resulting in the formation of a transparent hydrogel. ${ }^{18}$ Selfassembling peptide hydrogels consist of nanofibers and contain water up to $99.9 \%$ of their weight, within the porous nanofiber network. ${ }^{18}$ The ease of changing the peptide nanofiber density and the amino acid sequence of the peptides provides a means to control the diffusion rate of pharmaceutically active compounds. ${ }^{18}$ Self-assembling peptides contain natural amino acids resulting in hydrogels that are bioadsorbable and biodegradable and suitable for drug delivery applications.

In this study, the Ac-(RADA $)_{4}-\mathrm{CONH}_{2}$ and $\mathrm{Ac}-(\mathrm{IEIK})_{3} \mathrm{I}-\mathrm{CONH} \mathrm{H}_{2}$ self-assembling peptide nanofiber hydrogels differing in the number and type of amino acids in the sequence were tested as drug carriers of timolol maleate for the treatment of glaucoma. Both hydrogels comprise of alternating hydrophobic (A: alanine or I: isoleucine) and hydrophilic [R: arginine (+) and D: aspartic acid (-) or E: glutamic acid (-) and K: lysine (+)] amino acids. 


\title{
MATERIALS AND METHODS
}

Materials. Timolol maleate (purity $>98 \%$ ), acetonitrile, water $\left(\mathrm{CHROMASOLV}^{\circledR}\right.$, HPLC grade), sodium hydroxide $1 \mathrm{M}$, acetic acid, and triethylamine ( $>99.5 \%)$ were purchased from Sigma-Aldrich (Germany). Ac-(RADA) $)_{4}-\mathrm{CONH}_{2}$ and Ac-(IEIK) $)_{3} \mathrm{I}-\mathrm{CONH}{ }_{2}$ peptide solutions (1 $\% \mathrm{w} / \mathrm{v}$ ) were obtained by 3D-Matrix Inc., Japan.

\begin{abstract}
Animals. Albino New Zealand normotensive rabbits of either sex weighing 2-2.5 kg were used in the in vivo study. Animals were housed under standard conditions of temperature $\left(20-24{ }^{\circ} \mathrm{C}\right)$ and $12 \mathrm{~h}$ light/12 h dark cycle and were provided with food and water ad libitum. All animals were acclimated to the facilities for 7 days prior to admission to the experimental sessions. All procedures were approved by the local Ethics Committee of the Aristotle University of Thessaloniki, as well as by the Committee of the Department of Veterinary Medicine of Thessaloniki and conformed to the ARVO Statement for the Use of Animals in Ophthalmic and Vision Research and the European Communities Council Directive (86/609/EEC). The study was conducted in the Companion Animal Clinic, Faculty of Veterinary Medicine, Aristotle University of Thessaloniki. Before the study, a complete and thorough ophthalmic examination was performed in all rabbits to ensure that they were free of any ocular pathologic conditions.
\end{abstract}

Scanning Electron Microscopy (SEM) studies. Peptide hydrogel preparation for SEM imaging involved the slow exchange of the water in the hydrogels with ethanol in $10 \% \mathrm{v} / \mathrm{v}$ increment steps of increasing ethanol to water solutions for $60 \mathrm{~min}$ in each condition. When the hydrogel was in $100 \%$ ethanol, the ethanol was replaced with liquid $\mathrm{CO}_{2}$ using a $\mathrm{CO}_{2}$ critical point dryer (Balzers CPD 030). Once the substitution was complete, the samples were carefully affixed onto 
$12.5 \mathrm{~mm}$ SEM and coated with $~ 3 \mathrm{~nm}$ of Platinum (particle size $\sim 7 \mathrm{~nm}$; Quorum Q150T ES) and the nanofiber framework was visualized by SEM (FEI Quanta FEG 250 Scanning Electron Microscope).

Rheological measurements. The flow and viscoelastic behavior of the peptide nanofiber hydrogels Ac-(RADA) $)_{4}-\mathrm{CONH}_{2}$ and Ac-(IEIK $)_{3} \mathrm{I}-\mathrm{CONH}_{2}$ were examined on a rotational Physica MCR 300 rheometer (Physica Messtechnic GmbH, Stuttgart, Germany) using the cone and plate geometry (diameter $25 \mathrm{~mm}$, cone angle $1^{\circ}$, at a gap of $0.05 \mathrm{~mm}$ ). The temperature was regulated by a Paar Physica circulating bath and a controlled Peltier system (TEZ 150P/MCR) at $37 \pm 0.1^{\circ} \mathrm{C}$. A vapor trap was placed around the cone to prevent liquid evaporation. Two types of rheological measurements were performed: (a) isothermal gel curing events were probed at a strain level of $0.5 \%$ and a frequency of $1 \mathrm{~Hz}$ and (b) oscillatory measurements of G' (storage modulus), G' (loss modulus) and $\tan \delta\left(\mathrm{G}^{\prime}\right.$ '/G') were performed with a strain of $0.5 \%$ and a frequency range over $0.1-100 \mathrm{~Hz}$. The data were analyzed using the rheometer software US200 V2.21. For the measurements, $600 \mu \mathrm{L}$ of $1 \% \mathrm{w} / \mathrm{v}$ peptide solutions were placed on the rheometer plate and PBS pH 7.4 was added to form a peptide hydrogel of $0.9 \% \mathrm{w} / \mathrm{v}$.

\section{In vitro release studies of timolol maleate from self-assembling peptide nanofiber hydrogels.} In vitro release studies of timolol maleate through Ac-(RADA) $)_{4}-\mathrm{CONH}_{2}$ and Ac-(IEIK) $)_{3} \mathrm{I}-$ $\mathrm{CONH}_{2}$ peptide hydrogels were performed in PBS pH $7.4\left(\mathrm{NaCl}: 8 \mathrm{~g} / \mathrm{L}, \mathrm{Na}_{2} \mathrm{HPO}_{4}: 1.44 \mathrm{~g} / \mathrm{L}\right.$, $\left.\mathrm{KCl}: 0.2 \mathrm{~g} / \mathrm{L}, \mathrm{KH}_{2} \mathrm{PO}_{4}: 0.24 \mathrm{~g} / \mathrm{L}\right)$ and simulated tear fluid $\mathrm{pH} 7.4\left(\mathrm{NaCl}: 6.8 \mathrm{~g} / \mathrm{L}, \mathrm{NaHCO}_{3}: 2.2\right.$ $\left.\mathrm{g} / \mathrm{L}, \mathrm{CaCl}_{2} \cdot 2 \mathrm{H}_{2} \mathrm{O}: 0.08 \mathrm{~g} / \mathrm{L}, \mathrm{KCl}: 1.4 \mathrm{~g} / \mathrm{L}\right)$. Timolol maleate was dissolved in $45 \mu \mathrm{L}$ of the peptide solution, up to $2.7 \mathrm{mg} / \mathrm{mL}$, which represents the maximum solubility of timolol maleate in water 
and the solution was sonicated for 15 minutes. Gelation was induced by the addition of $5 \mu \mathrm{L}$ of PBS resulting in a peptide concentration of $0.9 \% \mathrm{w} / \mathrm{v}$. A total volume of $800 \mu \mathrm{L}$ of the release medium was slowly added on top of the hydrogel in an Eppendorf tube. At predetermined time intervals, $600 \mu \mathrm{L}$ of the supernatant solution were withdrawn and replaced with equal volume of freshly prepared and preconditioned at $37{ }^{\circ} \mathrm{C}$ PBS buffer. Samples were quantified by HPLC analysis.

Ex vivo permeation studies across porcine cornea. Fresh porcine eyes were collected from the local slaughterhouse and immediately immersed in PBS solution at $4{ }^{\circ} \mathrm{C}$. Permeability studies were performed within $30 \mathrm{~min}$ after removal of the eye. Macroscopically intact corneas were carefully excised and placed between the donor and the acceptor compartments of thermostated at $37{ }^{\circ} \mathrm{C}$ vertical Franz cells modified for corneal delivery (diffusion area: $0.19 \mathrm{~cm}^{2}$, Permegear, US). The receptor cell was filled with $3 \mathrm{~mL}$ glutathione bicarbonate Ringer's (GBR) solution $\mathrm{pH}$ 7.4 which was magnetically stirred. Glutathione bicarbonate Ringer's solution was prepared by mixing equal volumes of the following two solutions prior to use: the first solution consisted of sodium chloride $(12.4 \mathrm{~g} / \mathrm{L})$, potassium chloride $(0.716 \mathrm{~g} / \mathrm{L})$, sodium bicarbonate $(4.908 \mathrm{~g} / \mathrm{L})$ and monobasic sodium phosphate monohydrate $(0.206 \mathrm{~g} / \mathrm{L})$ and the second solution consisted of magnesium chloride hexahydrate $(0.318 \mathrm{~g} / \mathrm{L})$, calcium chloride dihydrate $(0.23 \mathrm{~g} / \mathrm{L})$, glucose $(1.8$ $\mathrm{g} / \mathrm{L})$ and oxidized glutathione $(0.184 \mathrm{~g} / \mathrm{L}) .{ }^{22,23}$ The donor compartment was filled with $90 \mu \mathrm{L}$ of each peptide nanofiber solution, containing $2 \mathrm{mg} / \mathrm{mL}$ of timolol maleate, and hydrated with 10 $\mu \mathrm{L}$ of PBS solution. Experiments were also performed with corneal tissues interacting with 100 $\mu \mathrm{L}$ of the timolol maleate solution $(2 \mathrm{mg} / \mathrm{mL})$ in PBS placed in the donor chamber. In control experiments, the tissues were allowed to interact with $100 \mu \mathrm{L}$ of the PBS solution. Samples of 
$400 \mu \mathrm{L}$ were withdrawn from the acceptor phase at predetermined time intervals up to $4 \mathrm{~h}$ and replaced with the same volume of fresh, preconditioned at $37{ }^{\circ} \mathrm{C}$ GBR solution. All experiments were performed in non-occlusive conditions to allow air permeation of the corneal tissues $(n \geq$ 3). Timolol maleate was quantified by HPLC.

HPLC assay. For the quantification of timolol maleate, a previously reported method was adapted. $^{24}$ The HPLC system consisted of a LC-10 AD VP pump, an autosampler model SIL20A HT equipped with a $100 \mu \mathrm{L}$ loop and a UV-vis detector model SPD-10A VP (Shimadzu, Kyoto, Japan). A SUPELCO LC-18-DB $5 \mu \mathrm{m}$ column was used (15 cm x $4.6 \mathrm{~mm})$. The mobile phase consisted of acetonitrile/water $(25: 75 \mathrm{v} / \mathrm{v})$. The aqueous phase contained $2.02 \mathrm{~g} / \mathrm{L}$ triethylamine and $10 \mathrm{~g} / \mathrm{L}$ acetic acid. The $\mathrm{pH}$ was adjusted to 4 with $\mathrm{NaOH}$. The flow rate was regulated at $0.8 \mathrm{~mL} / \mathrm{min}$, the injection volume was $90 \mu \mathrm{L}$ and timolol maleate was detected at $294 \mathrm{~nm}$. All solvents were filtered through $0.45 \mathrm{~mm}$ nylon membrane filters and degassed prior to use. Calibration curves of timolol maleate revealed linearity $\left(r^{2}>0.999\right)$ in the concentration ranges of $0.5-20 \mu \mathrm{g} / \mathrm{mL}$.

Ex vivo data analysis. The cumulative timolol maleate permeation per unit of corneal surface area $\left(\mu \mathrm{g} / \mathrm{cm}^{2}\right)$ was plotted as a function of time $(\mathrm{h})$. The steady state flux $J_{\mathrm{ss}}\left(\mu \mathrm{g} / \mathrm{cm}^{2} / \mathrm{h}\right)$ was calculated from the slope of the linear part of the curve. The apparent permeability coefficient $P_{\text {app }}(\mathrm{cm} / \mathrm{s})$ was calculated according to:

$$
P_{\mathrm{app}}=J_{s s} / \mathrm{C}_{\mathrm{d}}
$$

where $C_{\mathrm{d}}(\mu \mathrm{g} / \mathrm{mL})$ is the initial concentration of the diffusing compound in the donor cell. ${ }^{22}$ 
Corneal characterization. At the end of each permeation experiment, the tissues were carefully removed from the Franz cells and thoroughly washed with distilled water to remove the excess formulations and used for further characterization.

Hydration content. Excess water was blotted on a filter paper and corneal tissues from the ex vivo permeation studies were immediately weighted and dried overnight in an oven at $80{ }^{\circ} \mathrm{C}$. Dry tissues were weighted, and the hydration content was calculated according to the following equation: ${ }^{26}$

$$
\text { Hydration content }(\%)=W_{\text {initial }}-W_{\text {final }} / W_{\text {initial }}
$$

where $W_{\text {initial }}$ is the weight of corneas after 4 hours of ex vivo permeation studies and $W_{\text {final }}$ is the weight of the dry corneas.

Drug accumulation in corneal tissue. Corneas were homogenized in $5 \mathrm{~mL}$ PBS solution, centrifuged at 4,500 rpm for $30 \mathrm{~min}$ and the supernatants were syringe filtered and analyzed by HPLC. Drug retention was calculated as $\mu \mathrm{g} / \mathrm{cm}^{2}$, considering as active area the area available for permeation in the Franz cells (i.e. $0.19 \mathrm{~cm}^{2}$ ).

\footnotetext{
Histological studies. Corneas interacting with the control, the timolol maleate formulations in PBS and the peptide hydrogel from the ex vivo permeation experiments were fixed in $10 \%$ formalin, embedded in paraffin, and stained with hematoxylin and eosin. The specimens were analyzed in an Olympus CX31 optical microscope and images were taken using the OLYMPUS analySIS getIT software.
} 


\section{In vivo studies}

Intraocular pressure (IOP) measurements. Four rabbits $(n=4)$ were used for each treatment. IOP (mm Hg) was measured by the same operator using a Tono-Pen XL applanation tonometer (Reichert Technologies, NY, USA) after instillation of one drop of $0.5 \%$ proparacaine hydrochloride $\left(\right.$ Alcaine $^{\circledR}$, Alcon $^{\circledR}$ ) as topical anesthetic. To establish the normal baseline of each animal, the resting IOP of the eye to be treated was measured two days, one day, 30 min and 0 min prior to application of the timolol formulation. As suggested by previous studies, ${ }^{27}$ the baseline was established by the resting IOP of the eye to be treated. The contralateral eye of the animal was not taken as a control due to the existence of consensual commonly encountered in intraocular pressure studies, resulting in IOP changes of the untreated control eye upon treatment, as well. All measurements were recorded at the same time of the day by the same operator. At least three repeated readings for each eye were performed at each measurement and only measurements in which two consecutive readings were almost identical were included. When more than $2 \mathrm{~mm} \mathrm{Hg}$ of variation were recorded between measurements of an individual eye, animals were allowed to acclimate for 3 more minutes before repeating the measurement. The resting IOP values were averaged to establish the normal baseline of each animal. A single $100 \mu \mathrm{L}$ dose of $0.1 \% \mathrm{w} / \mathrm{v}$ timolol maleate peptide [ac-(RADA) $)_{4}-\mathrm{CONH}_{2}$, ac-(IEIK) $)_{3} \mathrm{I}-\mathrm{CONH}_{2}$ ] or physiological saline solution was instilled in the conjunctival sac of the treated eye using a calibrated automatic pipette and manually blinked three times. The IOP was measured at frequent time intervals following treatment. Changes in the IOP $(\triangle \mathrm{IOP})$ of the treated eyes were expressed as the difference from the baseline values at each time point and reported as mean values \pm standard error. 
Timolol maleate concentration in aqueous humor. All rabbits were randomly divided in three groups $(n=10)$. Each rabbit received a single instillation of $100 \mu \mathrm{L}$ of $0.1 \% \mathrm{w} / \mathrm{v}$ timolol maleate peptide hydrogel or timolol maleate saline solution in the conjunctival sac of both eyes (two rabbits per time point). Aqueous humor was collected by keratocentesis at $0 \mathrm{~min}, 15 \mathrm{~min}, 30$ min, $60 \mathrm{~min}$ and $120 \mathrm{~min}$ post-instillation under anesthesia, after thorough washing of the ocular surface with normal saline. Anesthesia was performed $20 \mathrm{~min}$ prior to sampling by intramuscular injection of ketamine $(20 \mathrm{mg} / \mathrm{kg})$ and dexmedetomidine $(150 \mu \mathrm{g} / \mathrm{kg})$. A 30-gause hypodermic needle with a syringe was directed through the limbal cornea into the anterior chamber and $200 \mu \mathrm{L}$ of aqueous humor were slowly aspirated. Timolol maleate was quantified in the aqueous humor with HPLC analysis as described in the HPLC assay section.

Ocular tolerance assay. In vivo ocular tolerance was assessed by the Draize eye test. ${ }^{28} \mathrm{~A}$ single instillation of $100 \mu \mathrm{L}$ of each formulation was administered in the conjunctival sac of the one eye, using the contralateral eye as the control $(n=4)$. Ophthalmic evaluation (cornea, iris and conjunctiva) was performed using a portable slit lamp (SL-15, Kowa, Tokyo, Japan) by three independent observers at $1 \mathrm{~h}, 8 \mathrm{~h}$ and $24 \mathrm{~h}$ after instillation. Eye irritation was classified according to four grades: practically non-irritating, score 0 - 3; slightly irritating, score 4 - 8; moderately irritating, score 9 - 12; and severely irritating (or corrosive), score 13 - 16.

\footnotetext{
Pharmacokinetic analysis. The pharmacokinetic parameters were calculated by using PKSolver (Microsoft Excel add-ins) for the pharmacokinetic analysis of mean concentration values from each group. Peak timolol maleate concentration $\left(\mathrm{C}_{\mathrm{max}}\right)$, area under the concentration vs. time curve (AUC) and peak time $\left(\mathrm{T}_{\max }\right)$ were the parameters computed.
} 
Histological evaluation. At the end of the pharmacokinetic study period one rabbit from each group was euthanized and both eyes were enucleated and further processed as described in the Histological studies section.

Statistical analysis. Data were analyzed using ANOVA to assess the presence of significant differences with the significance level set at 0.05 . Levene's test was used to assess homogeneity of variances. When the homogeneity test was not rejected, Bonferroni post hoc analysis was used to assess differences between groups. When Levene's test rejected the homogeneity of variances, the Welch test result was reported, and Dunnett's test was applied for post hoc analysis.

\section{RESULTS AND DISCUSSION}

Scanning electron microscopy studies. Scanning electron micrographs of Ac-(RADA $)_{4}$ $\mathrm{CONH}_{2}$ and $\mathrm{Ac}-(\mathrm{IEIK})_{3} \mathrm{I}-\mathrm{CONH}_{2}$ peptide nanofibers at low and high magnification are shown in Figure 1. Both peptides form a dense network of highly entangled nanofibers. A denser peptide nanofiber network was observed in the case of the Ac-(IEIK) $)_{3} \mathrm{I}-\mathrm{CONH}_{2}$ peptide assemblies compared with that observed in the case of the Ac-(RADA) $)_{4}-\mathrm{CONH}_{2}$ peptide hydrogel (Figure $1 \mathrm{C}$ and 1D).

Rheological measurements. The time-dependent response of G' and G' of the Ac-(RADA) ${ }_{4}^{-}$ $\mathrm{CONH}_{2}$ and Ac-(IEIK) $)_{3} \mathrm{I}-\mathrm{CONH}_{2}$ hydrogels recorded at $1 \mathrm{~Hz}$ frequency and $0.5 \%$ strain is shown in Figure 2A. Upon addition of the PBS buffer, the gelation process was monitored by the increase of G'. The Ac-(IEIK) $)_{3} \mathrm{I}-\mathrm{CONH}_{2}$ hydrogel was characterized by a faster rise of G' value 
suggesting that the formation of the three-dimensional nanofiber network occurred faster compared to that of Ac-(RADA) $)_{4}-\mathrm{CONH}_{2}$ hydrogel. Consistent to this observation is the $\tan \delta$ of the Ac-(IEIK) $)_{3} \mathrm{I}-\mathrm{CONH}_{2}$ hydrogel, which obtains values below 1 even at the initial stages of the gelation process (Figure 2B). The tan $\delta$ values obtained during the Ac-(RADA) $)_{4}-\mathrm{CONH}_{2}$ gelation drop below 1 only after an interval period of 12 minutes, suggesting a slower rate for the elastic-dominant behavior to be established. Minimum tan $\delta$ values were recorded at 0.120 and 0.098 for the Ac-(RADA) $)_{4}-\mathrm{CONH}_{2}$ and Ac-(IEIK) $)_{3} \mathrm{I}-\mathrm{CONH}_{2}$ hydrogels, respectively after 60 minutes from the addition of the PBS and the onset of gelation, suggesting the formation of a stiffer gel network for the Ac-(IEIK) $)_{3} \mathrm{I}-\mathrm{CONH}_{2}$ hydrogel. Similar loss tangent values were measured by Owczarz et al., ${ }^{29}$ while investigating the effect of increasing peptide concentration on the rheological properties of Ac-(RADA) $)_{4}-\mathrm{CONH}_{2}$ hydrogel at $\mathrm{pH} 2.0$.

At the end of the gel curing experiments, the mechanical properties of both hydrogels were recorded over the frequency range of $0.1 \mathrm{~Hz}$ to $100 \mathrm{~Hz}$ and at a strain level of $0.5 \%$ (Figure 2C). For gels, G' and G', are relatively constant with oscillatory frequency and G' being much greater than zero. ${ }^{30}$ The difference in gel stiffness observed between the two hydrogels could be attributed to the amino acid sequence resulting in the formation of different density peptide nanofibers. It has been previously reported that substitution of a hydrophobic residue (e.g., A) with a more hydrophobic one (e.g., I) results to a sequence with higher potency for self-assembly into hydrogel structures of higher stiffness. ${ }^{31}$ A slight increase in the stiffness of the Ac-(IEIK) $)_{3}$ I$\mathrm{CONH}_{2}$ hydrogel as compared with Ac-(RADA) $)_{4}-\mathrm{CONH}_{2}$ could be due to the replacement of R $(+)$ with $\mathrm{K}(+)$ and of D (-) with E (-). The increased hydrophobicity of I in the sequence of Ac$(\mathrm{IEIK})_{3} \mathrm{I}-\mathrm{CONH} \mathrm{H}_{2}$ as compared with $\mathrm{A}$ in $\mathrm{Ac}-(\mathrm{RADA})_{4}-\mathrm{CONH}_{2}$ is also correlated with faster response to the addition of the electrolyte solution, resulting in faster gel formation. 
The mechanical properties of both hydrogels bear similarities as shown in Figure 2C. Both hydrogels show the typical properties of elastic gel networks, with storage moduli being much higher than loss moduli over the entire frequency range and nearly independent of frequency. ${ }^{32}$

In vitro release of timolol maleate from self-assembling peptide nanofiber hydrogels. The release profiles of timolol maleate through Ac-(RADA) $)_{4}-\mathrm{CONH}_{2}$ and Ac-(IEIK) $)_{3} \mathrm{I}-\mathrm{CONH}_{2}$ hydrogels in simulated tear solution and in PBS are shown in Figures 3A and 3B. Timolol maleate was rapidly released through the Ac-(RADA) $)_{4}-\mathrm{CONH}_{2}$ hydrogel in PBS and was eliminated from the hydrogel after approximately $8 \mathrm{~h}$. A slower release profile was observed in the case of timolol maleate in the Ac-(IEIK) $)_{3} \mathrm{I}-\mathrm{CONH}_{2}$ hydrogel reaching a $60 \%$ release after 8 h. The difference observed in the rate and the total amount of timolol maleate released between the two hydrogels is likely due to the denser nanofiber network formed in the case of the Ac$(\mathrm{IEIK})_{3} \mathrm{I}-\mathrm{CONH}_{2}$ hydrogel compared with that in the Ac-(RADA) ${ }_{4}-\mathrm{CONH}_{2}$ hydrogel, as shown in the electron microscopy images and suggested by the rheological measurements. A denser nanofiber network retards the diffusion of the drug through the peptide hydrogel to the medium, as suggested previously, when the release profile of antibodies through the Ac-(RADA) $)_{4}-\mathrm{CONH}_{2}$ and Ac-(KLDL) $)_{3}-\mathrm{CONH}_{2}$ peptide hydrogels in PBS were compared ${ }^{19}$. Based on this observation, it is suggested that the release kinetics of a drug molecule may be fine-tuned by design of the amino acid sequence of the self-assembling peptides.

Both hydrogels demonstrated similar release patterns in simulated tear fluid. Within the first $4 \mathrm{~h}$ a burst release effect was observed, which however was less compared with that observed in the case of timolol maleate release in PBS, resulting in approximately $68 \%$ release of timolol maleate at the same timescale. A plateau in the release profile of timolol maleate in simulated 
tear fluid was observed after $12 \mathrm{~h}$ and reached approximately $72 \%$ release. The reduction in the drug diffusion rate in simulated tear fluid as compared with that in PBS was more pronounced in the case of timolol maleate released through the Ac-(RADA) $)_{4}-\mathrm{CONH}_{2}$ hydrogel. This could be due to the presence of calcium ions which are present in simulated tear fluid. It has been shown that the presence of calcium ions in the self-assembling process of amphiphilic peptides results in increased $\beta$-sheet formation, which in turn results in faster gelation and in hydrogel stabilization. 33, ${ }^{34}$ Mishra A. et al. (2013) demonstrated that the presence of divalent cations induced changes in the secondary structure of the peptide fibers, whereas monovalent cations had only negligible effects on the a-helical character of the Ac-LIVAGD and Ac-IVD peptide fibers. ${ }^{35}$

There was a statistically significant difference between the groups as determined by ANOVA $(\mathrm{F}=12.1, \mathrm{p}<0.001)$. A Bonferroni post hoc test revealed that the release of timolol maleate through Ac-(RADA) $)_{4}-\mathrm{CONH}_{2}$ in PBS was significantly faster than the release through Ac$(\text { IEIK })_{3} \mathrm{I}-\mathrm{CONH}{ }_{2}$ in PBS $(\mathrm{p}<0.001)$. There were no statistically significant differences in the release of timolol maleate between the Ac-(IEIK) $)_{3} \mathrm{I}-\mathrm{CONH}_{2}$ and $\mathrm{Ac}-(\mathrm{RADA})_{4}-\mathrm{CONH}_{2}$ groups in simulated tear fluid $(\mathrm{p}=1)$.

Ex vivo permeation studies across porcine cornea. Permeation profiles of timolol maleate in PBS pH 7.4 (control) and encapsulated in Ac-(RADA) $)_{4}-\mathrm{CONH}_{2}$ and Ac-(IEIK) $)_{3} \mathrm{I}-\mathrm{CONH}_{2}$ peptide nanofiber hydrogels across the corneal tissue are presented in Figure 4 (A schematic representation of the ex vivo study is illustrated at SI Figure S1). The permeability coefficient, $P_{\text {app }}$ and steady state flux values were calculated using Equations 1 and 2 and they are reported in Table 1.

The $P_{\text {app }}$ of timolol maleate in solution is $1.77 \pm 0.13 \times 10^{-6} \mathrm{~cm} / \mathrm{s}$, which is similar to the value 
reported previously for the timolol maleate permeability across porcine cornea (i.e., $\sim 0.9 \times 10^{-6}$ $\mathrm{cm} / \mathrm{s}) .{ }^{36}$ No statistically significant difference was observed in the permeation profile of timolol maleate in the Ac-(RADA) $)_{4}-\mathrm{CONH}_{2}$ hydrogel $\left(1.91 \pm 0.11 \times 10^{-6} \mathrm{~cm} / \mathrm{s}\right)$ compared with that of timolol maleate in solution $(\mathrm{p}=0.95)$. However, the $P_{\text {app }}$ of timolol maleate in the Ac-(IEIK) $)_{3} \mathrm{I}-$ $\mathrm{CONH}_{2}$ hydrogel was significantly lower (i.e., $0.71 \pm 0.15 \times 10^{-6} \mathrm{~cm} / \mathrm{s}$ ) compared to timolol maleate in solution, as determined by Dunnett $\mathrm{T} 3$ post hoc test $(\mathrm{p}=0.07)$. Drug penetration across corneal membrane in the presence of Ac-(IEIK) $)_{3} \mathrm{I}-\mathrm{CONH}_{2}$ followed a more sustained pattern, with a $J_{s s}$ value that is 2.5 times less than the respective $J_{s s}$ value of that calculated for the permeation of timolol maleate in the Ac-(RADA $)_{4}-\mathrm{CONH}_{2}$ formulation. The slower timolol maleate diffusion from the stiffer Ac-(IEIK) $)_{3} \mathrm{I}-\mathrm{CONH}_{2}$ nanofiber hydrogel, which acts as a drug reservoir system, appears to be the rate-regulating factor for the permeation of timolol maleate.

The corneal physiology evokes loss of instilled drug compounds due to tear turnover, drainage and non-corneal absorption. Therefore, an inevitable reduction in local drug bioavailability is expected. ${ }^{37}$ Formulations that increase the drug residency in the conjunctiva sac, while at the same time enable control of the drug release rate, may act as drug reservoirs creating a concentration gradient. This allows for lower administration frequency which increases patient compliance and therapeutic efficacy.

Hydration content. Corneal water content constitutes an indication of both epithelium and endothelium integrity. Literature values suggest a physiological hydration content in the range between $73 \%$ and $80 \%,{ }^{26,38}$ for intact porcine corneas, with damaged tissues possessing increased water content values. ${ }^{39}$ The hydration content of the tissues used in the permeation experiments of timolol maleate in solution and in the Ac-(RADA) $)_{4}-\mathrm{CONH}_{2}$ and Ac-(IEIK) $)_{3} \mathrm{I}-$ 
$\mathrm{CONH}_{2}$ nanofiber hydrogels were determined and were found to be in good agreement with the physiological values of intact tissues (Table 2).

Timolol maleate retention in corneal tissue. Drug penetration across corneal tissue is primarily regulated by a three-layered barrier, comprising of the lipophilic epithelium, the hydrophilic stroma and the endothelium structure, with the latter having a minor contribution as permeation regulator. ${ }^{40}$ Timolol maleate accumulation in corneal tissue was found to be highly correlated with the rate of drug release. Therefore, the Ac-(IEIK) $)_{3} \mathrm{I}-\mathrm{CONH}_{2}$ hydrogel, which showed the slowest release kinetics of timolol maleate, also reported the lowest drug retention values (45.23 $\pm 19.70 \mu \mathrm{g} / \mathrm{cm}^{2}$ ) compared to those obtained for treated tissues with timolol maleate in Ac$(\text { RADA })_{4}-\mathrm{CONH}_{2}\left(81.26 \pm 10.96 \mu \mathrm{g} / \mathrm{cm}^{2}\right)$ and timolol maleate in PBS solution $(93.33 \pm 11.96$ $\mu \mathrm{g} / \mathrm{cm}^{2}$ ) (Table 2). Effective drug distribution to all the internal eye tissues is achieved upon drug permeation across the cornea. Therefore, increased drug accumulation in the superficial eye tissues (e.g. cornea) is highly desirable, creating a drug reservoir. ${ }^{41}$

Histological studies. The integrity of the corneal tissue was further evaluated with histological examination upon the completion of the ex vivo permeation studies. Previous reports have shown a time dependent apical tissue abrasion which was characterized by mild loosening of the epithelial barrier and preservation of the stromal integrity in buffer solution $\mathrm{pH} 7.4$ after 2 hours of permeation experiments. ${ }^{38}$ No structural defects were observed during the permeation experiments in corneas treated with PBS after 4 hours in Franz cells (Figure 5A). Detachment of the apical epithelial layer was observed in Figure 5B in the cornea treated with the timolol maleate solution. Previously, clinical studies using ocular application of different salt forms of 
timolol (maleate and hemihydrate) showed higher ocular irritation of the corneal epithelium from the maleate salt form. ${ }^{42}$ Partial desquamation of the superficial epithelial cell layers was observed in the case of Ac-(RADA) $4-\mathrm{CONH}_{2}$ treated corneas (Figure 5C). Corneal integrity was preserved for Ac-(IEIK) $)_{3} \mathrm{I}-\mathrm{CONH}_{2}$ treated tissue, as shown in Figure 5D with only minor localized spongiosis visible.

IOP measurements. The pharmacodynamic effect of timolol maleate was evaluated after single instillation of $0.1 \%$ of timolol maleate in situ gel-forming peptide solutions, compared with timolol maleate in saline solution and was monitored as changes in IOP versus time (Figure 6). Both Ac-(RADA) $)_{4}-\mathrm{CONH}_{2}$ and Ac-(IEIK) $)_{3} \mathrm{I}-\mathrm{CONH}_{2}$ drug formulations demonstrated an IOPlowering effect within 30 min post-instillation, exhibiting a maximum IOP reduction at $1 \mathrm{~h}$. A similar pharmacodynamic profile was recorded for the timolol maleate solution up to $2 \mathrm{~h}$. The IOP lowering effect for the saline solution started to recover after $2 \mathrm{~h}$, whereas timolol in Ac$(\mathrm{RADA})_{4}-\mathrm{CONH}_{2}$ and in Ac-(IEIK) $)_{3} \mathrm{I}-\mathrm{CONH}_{2}$ sustained an effective IOP lowering effect for up to $24 \mathrm{~h}$. The higher ocular hypotensive effect produced by the in situ gel-forming peptide formulations is attributed to their better retention in the conjunctival area compared to that of the timolol saline solution, preventing the rapid elimination of the drug from the ocular surface and therefore, improving the ocular bioavailability and pharmacokinetics of timolol maleate.

Ocular penetration of timolol maleate to the aqueous humor. The concentration of timolol maleate in the aqueous humor of New Zealand white rabbits was determined at different timepoints following single administration of $0.1 \%$ timolol maleate peptide and saline solutions (Figure 7). The aqueous humor pharmacokinetic parameters of all tested formulations are 
summarized in Table 3. Both timolol maleate in Ac-(RADA $)_{4}-\mathrm{CONH}_{2}$ and in Ac-(IEIK) $)_{3} \mathrm{I}-$ $\mathrm{CONH}_{2}$ peptide formulations yielded significantly higher drug $\mathrm{C}_{\max }$ values than timolol in saline solution, as determined by the Welch test performed within Welch ANOVA $(\mathrm{F}=55.2, \mathrm{p}<0.001)$. A Dunnett T3 post hoc test revealed that the concentration of timolol in saline over time was statistically significantly different compared with that observed in the case of timolol released through the Ac-(IEIK) $)_{3} \mathrm{I}-\mathrm{CONH}_{2}$ and Ac-(RADA $)_{4}-\mathrm{CONH}_{2}$ peptide hydrogels $(\mathrm{p}<=0.001)$. Furthermore, statistically significant differences in timolol maleate concentration in the aqueous humor were identified for timolol maleate released through the Ac-(RADA) $4-\mathrm{CONH}_{2}$ and Ac$(\mathrm{IEIK})_{3} \mathrm{I}-\mathrm{CONH}{ }_{2}$ peptide hydrogels $(\mathrm{p}=0.015)$. Peak drug levels in the aqueous humor were observed at 30 min post-instillation for Ac-(RADA) $)_{4}-\mathrm{CONH}_{2} /$ timolol maleate and Ac-(IEIK) $)_{3} \mathrm{I}-$ $\mathrm{CONH}_{2} /$ timolol maleate peptide hydrogels and were found to be $3.07 \mu \mathrm{g} / \mathrm{mL}$ and $1.36 \mu \mathrm{g} / \mathrm{mL}$, accounting for a 4.58- and 2.03-fold increase, respectively, relative to timolol maleate in saline solution. The same $\mathrm{T}_{\max }$ value for timolol maleate has been previously reported after topical administration to the eye of a poly(N-isopropylacrylamide)-chitosan hydrogel formulation. ${ }^{43}$

The substantial enhancement of timolol maleate permeation to the aqueous humor could be attributed to the hydrogels' capability to prolong drug's residency on the corneal epithelium. At the same time, timolol in Ac-(IEIK) $)_{3} \mathrm{I}-\mathrm{CONH}_{2}$ reported a lower $\mathrm{C}_{\max }$ value compared to timolol maleate in Ac-(RADA) $)_{4}-\mathrm{CONH}_{2}$ owing to the slower drug diffusion rate from the peptide hydrogel, as already demonstrated in the in vitro release and ex vivo permeation studies.

The $\mathrm{AUC}_{0 \rightarrow 2}$ of timolol maleate in $\mathrm{Ac}-(\mathrm{RADA})_{4}-\mathrm{CONH}_{2}$ formulation was considerably higher to that of timolol maleate in $\mathrm{Ac}-(\mathrm{IEIK})_{3} \mathrm{I}-\mathrm{CONH}_{2}$ peptide and timolol maleate saline solution, resulting in higher drug ocular bioavailability, which in turn might reduce drug's systemic absorption. Notably, both Ac-(IEIK) $)_{3} \mathrm{I}-\mathrm{CONH}_{2}$ peptide hydrogel and saline solution drug 
formulations exhibited similar AUC values, however the Ac-(IEIK) $)_{3} \mathrm{I}-\mathrm{CONH}_{2}$ peptide hydrogel demonstrated a significantly higher $\mathrm{C}_{\max }$ suggesting a faster rate of timolol maleate ocular absorption.

Ocular tolerance assay. According to the Draize scoring system all tested formulations were classified as non-irritant (total score: 0), since no indication of conjunctival, iris or corneal irritative reaction was observed at all-time points of analysis (1h, $8 \mathrm{~h}$ and $24 \mathrm{~h}$ ), signifying their appropriateness for ocular administration.

Histological evaluation. Histological analysis of the corneal sections at $2 \mathrm{~h}$ post treatment with the tested formulations is shown in Figure 8. All formulations demonstrated good tolerability with no notable changes in the structural integrity of epithelium, stroma and endothelium. The discrepancy between the ex vivo and the in vivo histological findings might be attributed to the static conditions and the absence of nasolacrimal drainage during ex vivo experimentation, which is not the case in the in vivo system. Overall, both Ac-(RADA) $)_{4}-\mathrm{CONH}_{2}$ and Ac-(IEIK) $)_{3}$ I$\mathrm{CONH}_{2}$ peptide hydrogels could be considered safe for ocular drug delivery.

\section{CONCLUSIONS}

Ac-(RADA) $)_{4}-\mathrm{CONH}_{2}$ and Ac-(IEIK) $)_{3} \mathrm{I}-\mathrm{CONH}_{2}$ self-assembling peptide hydrogels were tested as carriers of timolol maleate for ocular drug delivery. The Ac-(IEIK) $)_{3} \mathrm{I}-\mathrm{CONH}_{2}$ hydrogel showed a slower release pattern of timolol maleate compared with the Ac-(RADA) ${ }_{4}-\mathrm{CONH}_{2}$ drug formulation. This form of control over drug's diffusion rate was also observed in timolol maleate's ex vivo permeation profile across porcine cornea. The current study shows that by 
changing the amino acid sequence of the self-assembling peptide hydrogels we may fine-tune the release profile of timolol maleate. The safety of the system was confirmed by histological evaluation, Draize test and physicochemical characterization of corneas treated with the timolol maleate peptide hydrogel formulations showing good biocompatibility properties. Moreover, in vivo pharmacokinetic and pharmacodynamic studies demonstrated that Ac-(RADA) ${ }_{4}-\mathrm{CONH}_{2}$ can significantly enhance the bioavailability of timolol maleate, achieving effective IOP reduction for up to $24 \mathrm{~h}$. Overall, our results suggest the potential therapeutic utility of Ac-(RADA) $4^{-}$ $\mathrm{CONH}_{2}$ peptide hydrogel as a safe drug delivery system for ophthalmic use, that is capable of enhancing drug bioavailability and achieving a sustained IOP lowering effect, therefore reducing the frequency of administration and conceivably improving patience compliance. Further research is encouraged to comprehensively assess self-assembling peptide hydrogels for their beneficial pertinency in the treatment of other chronic ocular diseases.

\section{ASSOCIATED CONTENT}

\section{Supporting information}

Figure S1 depict a schematic representation of the ex vivo experiment across porcine cornea.

\section{AUTHOR INFORMATION}

\section{Corresponding Authors:}

Dr. Dimitrios G. Fatouros: e-mail: dfatouro@pharm.auth.gr, Tel: +30 2310 997653, Fax: +30 2310997652

Dr. Sotirios Koutsopoulos: e-mail: sotiris@mit.edu, Tel: +1-617-752-2042, Fax: +1-617-2585239

These authors contributed equally. 


\section{Author Contributions}

The manuscript was written through contributions of all authors. All authors have given approval to the final version of the manuscript.

\section{Funding Sources}

Part of this work was funded by the Research Committee of Aristotle University of Thessaloniki (\#90633).

\section{ACKNOWLEDGMENT}

C.K. is supported by the Onassis Foundation with a PhD scholarship. We would like to thank Dr. T. Moschaki and Dr. A. Lazaridou for their assistance in the rheology measurements and Mrs. P. Anastasiadou for her technical assistance with the histochemical studies. We also like to acknowledge the Biomedical Imaging Unit at the University Hospital Southampton for the provision of the imaging (SEM) facilities and Dr. Anton Page and Dr. Lizzie Angus for the input during sample preparation. We also like to thank Dr. Sofia Michopoulou (University Hospital Southampton) for the invaluable help with the statistical analysis of the data. 


\section{REFERENCES}

(1) Gaudana, R.; Jwala, J.; Boddu, S.H.; Mitra, A.K. Recent perspectives in ocular drug delivery. Pharm. Res. 2009, 26, 1197 - 1216.

(2) Chang, J.N. In Handbook of non-invasive drug delivery systems. V.S. Kulkarni Eds.; Elsevier, 2010; p 165 - 186.

(3) Keister, J.C.; Cooper, E.R.; Missel, P.J.; Lang, J.C.; Hager, D.F. Limits on optimizing ocular drug delivery. J. Pharm. Sci. 1991, 80, 50 - 53.

(4) Kirchhof, S.; Goepferich, A.M.; Brandl, F.P. Hydrogels in ophthalmic applications. Eur. J. Pharm. Biopharm. 2015, 95 (PtB), 227 - 238.

(5) Kaur, I.P.; Kanwar, M. Ocular preparations: the formulation approach. Drug Dev. Ind. Pharm. 2002, 28, 473 - 493.

(6) Gurny, R.; Boye, T.; Ibrahim, H.J. Ocular therapy with nanoparticulate systems for controlled drug delivery. J. Control. Release 1985, 2, 353 - 361.

(7) Miller, S.C.; Donovan, M.D. Effect of poloxamer 407 gel on the miotic activity of pilocarpine nitrate in rabbits. Int. J. Pharm. 1982, 12, 147 - 152.

(8) El-Kamel; A.H. In vitro and in vivo evaluation of Pluronic F127-based ocular delivery system for timolol maleate. Int. J. Pharm. 2002, 241, 47 - 55.

(9) MacKeen, D.L. Aqueous formulations and ointments. Int. Ophthalmol. Clin. 1980, 20, 79 92.

(10) Karataş, A.; Algan, A.H.; Pekel-Bayramgil, N.; Turhan, F.; Altanlar, N. Ofloxacin Loaded Electrospun Fibers for Ocular Drug Delivery: Effect of Formulation Variables on Fiber Morphology and Drug Release. Curr Drug Deliv. 2016, 13, 433-443. 
(11) Mehta, P.; Al-Kinani, A.A.; Arshad, M.S.; Chang, M.W.; Alany, R.G.; Ahmad, Z. Development and characterisation of electrospun timolol maleate-loaded polymeric contact lens coatings containing various permeation enhancers. Int J Pharm. 2017, 532, 408-420.

(12) Mehta, P.; Al-Kinani, A.A.; Haj-Ahmad, R.; Arshad, M.S.; Chang, M.W.; Alany, R.G.; Ahmad, Z. Electrically atomized formulations of timolol maleate for direct and on-demand ocular lens coatings. Eur J Pharm Biopharm. 2017, 119, 170-184.

(13) Koutsopoulos, S. Self-assembling peptide nanofiber hydrogels in tissue engineering and regenerative medicine: progress, design guidelines, and applications. J. Biomed. Mater. Res. A 2016, 104, $1002-1016$.

(14) Koutsopoulos, S.; Zhang, S. Long-term three-dimensional neural tissue cultures in functionalized self-assembling peptide hydrogels, Matrigel and Collagen I. Acta Biomater. 2013, 9, $5162-5169$.

(15) Davis, M.E.; Hsieh, P.C.H.; Takahashi, T.; Song, Q.; Zhang, S.; Kamm, R.D.; Grodzinsky, A.J.; Anversa, P.; Lee, R.T. Local myocardial insulin-like growth factor 1 (IGF-1) delivery with biotinylated peptide nanofibers improves cell therapy for myocardial infraction. Proc. Natl. Acad. Sci. USA 2006, 103, 8155 - 8160.

(16) Koutsopoulos, S. Molecular fabrications of smart nanobiomaterials and applications in personalized medicine. Adv. Drug Deliv. Rev. 2012, 64, 1459 - 1476.

(17) Nagai, Y.; Unsworth, L.D.; Koutsopoulos, S.; Zhang, S. Slow release of molecules in selfassembling peptide nanofiber scaffold. J. Control. Release 2006, 115, 18 - 25.

(18) Koutsopoulos, S.; Unsworth, L.D.; Nagai, Y.; Zhang, S. Controlled release of functional proteins through designer self-assembling peptide nanofiber hydrogel scaffold. Proc. Natl. Acad. Sci. USA 2009, 106, 4623 - 4628. 
(19) Koutsopoulos, S.; Zhang, S. Two-layered injectable self-assembling peptide scaffold hydrogels for long-term sustained release of human antibodies. J. Control. Release 2012, 160, $451-458$.

(20) Altunbas, A.; Lee, S.J.; Rajasekaran, S.A.; Schneider, J.P.; Pochan, D.J. Encapsulation of curcumin in self-assembling peptide hydrogels as injectable drug delivery vehicles. Biomaterials 2011, 32, $5906-5914$.

(21) Liu, J.; Zhang, L.; Yang, Z.; Zhao, X. Controlled release of paclitaxel from a selfassembling peptide hydrogel formed in situ and antitumor study in vitro. Int. J. Nanomedicine 2011, 6, 2143 - 2153.

(22) Lin, H.H.; Ko, S.M.; Hsu, L.R.; Tsai, Y.H. The preparation of norfloxacin-loaded liposomes and their in vitro evaluation in pig's eye. J. Pharm. Pharmacol. 1996, 48, 801-805.

(23) Liu J, Fu S, Wei N, Hou Y, Zhang X, Cui H. The effects of combined menthol and borneol on fluconazole permeation through the cornea ex vivo. Eur. J. Pharmacol. 2012, 688, 1-5.

(24) Fatouros, D.G.; Bouwstra, J.A. Iontophoretic enhancement of timolol across human dermatomed skin in vitro. J. Drug Target. 2004, 12, 19 - 24.

(25) Pescina, S.; Govoni, P.; Antopolsky, M.; Murtomäki, L.; Padula, C.; Santi, P.; Nicoli, S. Permeation of proteins, oligonucleotide and dextrans across ocular tissues: experimental studies and a literature update. J. Pharm. Sci. 2015, 104, 2190 - 2202.

(26) Xu, Y.G.; Xu, Y.S.; Huang, C.; Feng, Y.; Li, Y.; Wang, W. Development of a rabbit corneal equivalent using an acellular corneal matrix of a porcine substrate. Mol. Vis. 2008, 14, 2180 2189. 
(27) Kassem, M.A.; Rahman, A.A.; Ghorab, M.M.; Ahmed, M.B.; Khalil, R.M.; Nanosuspension as an ophthalmic delivery system for certain glucocorticoid drugs. Int. J. Pharm. 2007, 340, 126 $-133$.

(28) Draize, J.H.; Woodard, G.; Calvery, H.O. Methods for the study of irritation and toxicity of substances applied topically to the skin and mucous membranes. J. Pharmacol. Exp. Ther. 1944, $82,377-390$.

(29) Owczarz, M.; Bolisetty, S.; Mezzenga, R.; Arosio, P. Sol-gel transition of charged fibrils composed of a model amphiphilic peptide. J. Colloid Interface Sci. 2015, 437, 244 - 251.

(30) Clark, A.H.; Ross-Murphy, S.B. In: Biopolymers. Advances in Polymer Science, vol 83. Springer, Berlin, Heidelberg Springer-Verlag: Berlin, 1987; p 57-192.

(31) Zhang, S. Emerging biological materials through molecular self-assembly. Biotechnol. Adv. 2002, 20, $321-339$.

(32) Anseth, K.S.; Bowman, C.N.; Brannon-Peppas, L. Mechanical properties of hydrogels and their experimental determination. Biomaterials. 1996, 17, 1647 - 1657.

(33) Zarzhitsky, S.; Edri, H.; Azoulay, Z.; Cohen, I.; Ventura, Y.; Gitelman, A.; Rapaport, H. The effect of $\mathrm{pH}$ and calcium ions on the stability of amphiphilic and anionic $\beta$-sheet peptide hydrogels. Biopolymers. 2013, 100, 760 - 772.

(34) Caplan, M.R.; Moore, P.N.; Zhang, S.; Kamm, R.D.; Lauffenburger, D.A. Self-assembly of a $\beta$-sheet protein governed by relief of electrostatic repulsion relative to van der Waals attraction. Biomacromolecules. 2000, 1, 627 - 631 .

(35) Mishra, A.; Chan, K.H.; Reithofer, M.R.; Hauser, C.A.E.; Influence of metal salts on the hydrogelation properties of ultrashort aliphatic peptides. $R S C A d v$. 2013, 3, 9985 - 9993. 
(36) Arnold, J.J.; Hansen, M.S.; Gorman, G.S.; Inoue, T.; Rao, V.; Spellen, S.; Hunsinger, R.N.; Chapleau, C.A.; Pozzo-Miller, L.; Stamer, W.D.; Challa, P. The effect of Rho-associated kinase inhibition on the ocular penetration of timolol maleate. Invest. Ophthalmol. Vis. Sci. 2013, 54, $1118-1126$.

(37) Burstein, N.L.; Anderson J.A. Corneal penetration and ocular bioavailability of drugs. $J$. Ocul. Pharmacol. 1985, 1, 309 - 326.

(38) Pescina, S.; Govoni, P.; Potenza, A.; Padula, C.; Santi, P.; Nicoli, S. Development of a convenient ex vivo model for the study of the transcorneal permeation of drugs: histological and permeability evaluation. J. Pharm. Sci. 2015, 104, 63 - 71.

(39) Monti, D.; Chetoni, P.; Burgalassi, S.; Najarro, M.; Saettone M.F. Increased corneal hydration induced by potential ocular penetration enhancers: assessment by differential scanning calorimetry (DSC) and by desiccation. Int. J. Pharm. 2002, 232, 139 - 147.

(40) Jarvinen, K.; Jarvinen, T.; Urtti, A. Ocular absorption following topical delivery. Adv. Drug Deliv. Rev. 1995, 16, 3 -19.

(41) Washington, N.; Washington, C.; Wilson, C.G. Physiological Pharmaceutics: Barriers to Drug Absorption. Taylor and Francis (2001).

(42) Stewart, W.C.; Stewart, J.A.; Holmes, K.T.; Leech, J.N. Differences in ocular surface irritation between timolol hemihydrate and timolol maleate. Am J. Ophthalmol. 2000, 130, 712 716.

(43) Cao, Y.; Zhang, C.; Shen, W.; Cheng, Z.; Yu, L.L.; Ping, Q. Poly(N-isopropylacrylamide)chitosan as thermosensitive in situ gel-forming system for ocular drug delivery. J. Control. Release. 2007, 120, 186 - 194. 
Table 1. Apparent permeability coefficient $\left(P_{\text {app }}\right)$ and steady state flux $\left(J_{s s}\right)$ values of timolol maleate in excised porcine corneas. Data are expressed as mean \pm standard deviation $(\mathrm{n} \geq 3)$.

\begin{tabular}{lccc}
\hline Formulation & $\mathbf{C}(\mathbf{m g} / \mathbf{m L})$ & $\boldsymbol{J}_{\mathbf{s s}}\left(\boldsymbol{\mu g} / \mathbf{c m}^{2} / \mathbf{m i n}\right)$ & $\boldsymbol{P}_{\text {app }}\left(\mathbf{1 0}^{-\mathbf{6}}\right) \mathbf{~ c m} / \mathbf{s}$ \\
\hline Timolol maleate solution in PBS & 2 & $0.213 \pm 0.021$ & $1.77 \pm 0.13$ \\
Ac-(RADA) 4 -CONH$/$ timolol maleate & 2 & $0.230 \pm 0.010$ & $1.91 \pm 0.11$ \\
& & & \\
Ac-(IEIK) 3 I-CONH & & & \\
& 2 & $0.086 \pm 0.012$ & $0.71 \pm 0.15$ \\
\hline
\end{tabular}


Table 2. Corneal hydration content values and drug retention in treated corneas extracted after tissue homogenization. Data are expressed as mean \pm standard deviation $(n=4)$.

Ac-(RADA) $)_{4}-\mathrm{CONH}_{2} /$ timolol maleate

$80.73 \pm 0.66$

$81.26 \pm 10.96$

Ac-(IEIK) $)_{3} \mathrm{I}-\mathrm{CONH}_{2} /$ timolol maleate 
Table 3. Pharmacokinetic parameters of timolol maleate in aqueous humor after topical administration of $0.1 \%$ timolol maleate formulations in rabbits $(n=4)$.

\begin{tabular}{lccc}
\hline Formulation & $\mathbf{A U C}_{\mathbf{0} \rightarrow \mathbf{2}}( \pm \mathbf{S . D})$. & $\mathbf{C}_{\mathbf{m a x}}$ & $\mathbf{T}_{\mathbf{m a x}}$ \\
& $(\boldsymbol{\mu g} \cdot \mathbf{m i n} / \mathbf{m l})$ & $(\boldsymbol{\mu g} / \mathbf{m L})$ & $(\mathbf{m i n})$ \\
\hline Ac-(IEIK) ${ }_{3} \mathrm{I}-\mathrm{CONH}_{2} /$ timolol maleate & $57.26 \pm 7.47$ & $1.36 \pm 0.15$ & 30 \\
Ac-(RADA) ${ }_{4}-\mathrm{CONH}_{2} /$ timolol maleate & $172.43 \pm 17.04$ & $3.07 \pm 0.45$ & 30 \\
Timolol maleate/saline & $56.11 \pm 7.79$ & $0.67 \pm 0.11$ & 60 \\
\hline
\end{tabular}

$\mathrm{AUC}_{0 \rightarrow 2}$, area under the curve, 0 - 2 hours; $\mathrm{C}_{\max }$, maximum concentration; $\mathrm{T}_{\max }$, time to $\mathrm{C}_{\max }$ 


\section{FIGURE LEGENDS}

FIGURE 1: Scanning electron micrographs of $(\mathbf{A}, \mathbf{B})$ Ac-(RADA $)_{4}-\mathrm{CONH}_{2},(\mathbf{C}, \mathbf{D})$ Ac-(IEIK) $)_{3} \mathrm{I}-\mathrm{CONH}_{2}$ peptide nanofiber hydrogels.

FIGURE 2: Mechanical properties of the peptide hydrogels. Time dependence of (A) $\mathrm{G}^{\prime}$ and $(\mathbf{B}) \tan \delta$ for Ac-(RADA) ${ }_{4}-\mathrm{CONH}_{2}$ and $\mathrm{Ac}-(\mathrm{IEIK})_{3} \mathrm{I}-\mathrm{CONH}_{2}$ peptide nanofiber hydrogels $\left(1 \mathrm{~Hz}, 0.5 \%\right.$ strain, $\left.37^{\circ} \mathrm{C}\right)$ and $(\mathbf{C})$ frequency dependence of $\mathrm{G}$ ' and $\mathrm{G}$ " of the formed peptide nanofiber hydrogels (strain $0.5 \%, 37^{\circ} \mathrm{C}$ ).

FIGURE 3: In vitro release study of timolol maleate through Ac-(RADA) $4-\mathrm{CONH}_{2}$ and Ac-(IEIK) $)_{3} \mathrm{I}-\mathrm{CONH}_{2}$ peptide nanofiber hydrogels in (A) PBS pH 7.4 and (B) simulated tear fluid. All experiments were performed at $37^{\circ} \mathrm{C}(\mathrm{n}=3)$.

FIGURE 4: Permeation profiles of timolol maleate solution, Ac-(RADA) $)_{4}-\mathrm{CONH}_{2}$ /timolol maleate peptide nanofiber hydrogel and Ac-(IEIK) ${ }_{3} \mathrm{I}-\mathrm{CONH}_{2} /$ timolol maleate peptide nanofiber hydrogel across porcine corneas $(n \geq 3)$.

FIGURE 5: Histological sections of porcine corneas after 4-hour treatment with (A) PBS (control), (B) timolol maleate solution in PBS, (C) Ac-(RADA) $4-\mathrm{CONH}_{2} /$ timolol maleate peptide nanofiber hydrogel and (D) Ac-(IEIK) $)_{3} \mathrm{I}-\mathrm{CONH}_{2} /$ timolol maleate peptide nanofiber hydrogel. (ep: epithelium; Bw: Bowman's layer; st: stroma. Scale bar $100 \mu \mathrm{m})$.

FIGURE 6: IOP reduction in normotensive white New Zealand rabbits after treatment with $0.1 \%$ Ac-(RADA) $)_{4}-\mathrm{CONH}_{2} /$ timolol maleate peptide nanofiber hydrogel $(\bullet)$, Ac- 
$(\mathrm{IEIK})_{3} \mathrm{I}-\mathrm{CONH} \mathrm{H}_{2} /$ timolol maleate peptide nanofiber hydrogel $(\boldsymbol{\Delta})$ and timolol maleate/saline solution ( $\mathbf{\square})$. Data are expressed as mean \pm standard error $(n=4)$.

FIGURE 7: Aqueous humor levels of timolol maleate after topical administration of $0.1 \%$ Ac- $(\mathrm{RADA})_{4}-\mathrm{CONH}_{2} /$ timolol maleate peptide nanofiber hydrogel $(\bullet)$, Ac$(\mathrm{IEIK})_{3} \mathrm{I}-\mathrm{CONH} \mathrm{C}_{2} /$ timolol maleate peptide nanofiber hydrogel $(\boldsymbol{\Delta})$ and timolol maleate/saline solution ( $\boldsymbol{\square})$. Data are expressed as mean \pm standard error $(n=4)$.

FIGURE 8: Histological sections of rabbit corneas instilled with different formulations (A) untreated eye (control), (B) timolol maleate/saline solution, (C) Ac-(RADA)4$\mathrm{CONH}_{2} /$ timolol maleate peptide nanofiber hydrogel and (D) Ac-(IEIK) $)_{3} \mathrm{I}-$ $\mathrm{CONH}_{2} /$ timolol maleate peptide nanofiber hydrogel. (ep: epithelium; Bw: Bowman's layer; st: stroma; Ds: Descemet's membrane; ed: endothelium. Scale bar: $100 \mu \mathrm{m}$ ). 
FIGURE 1

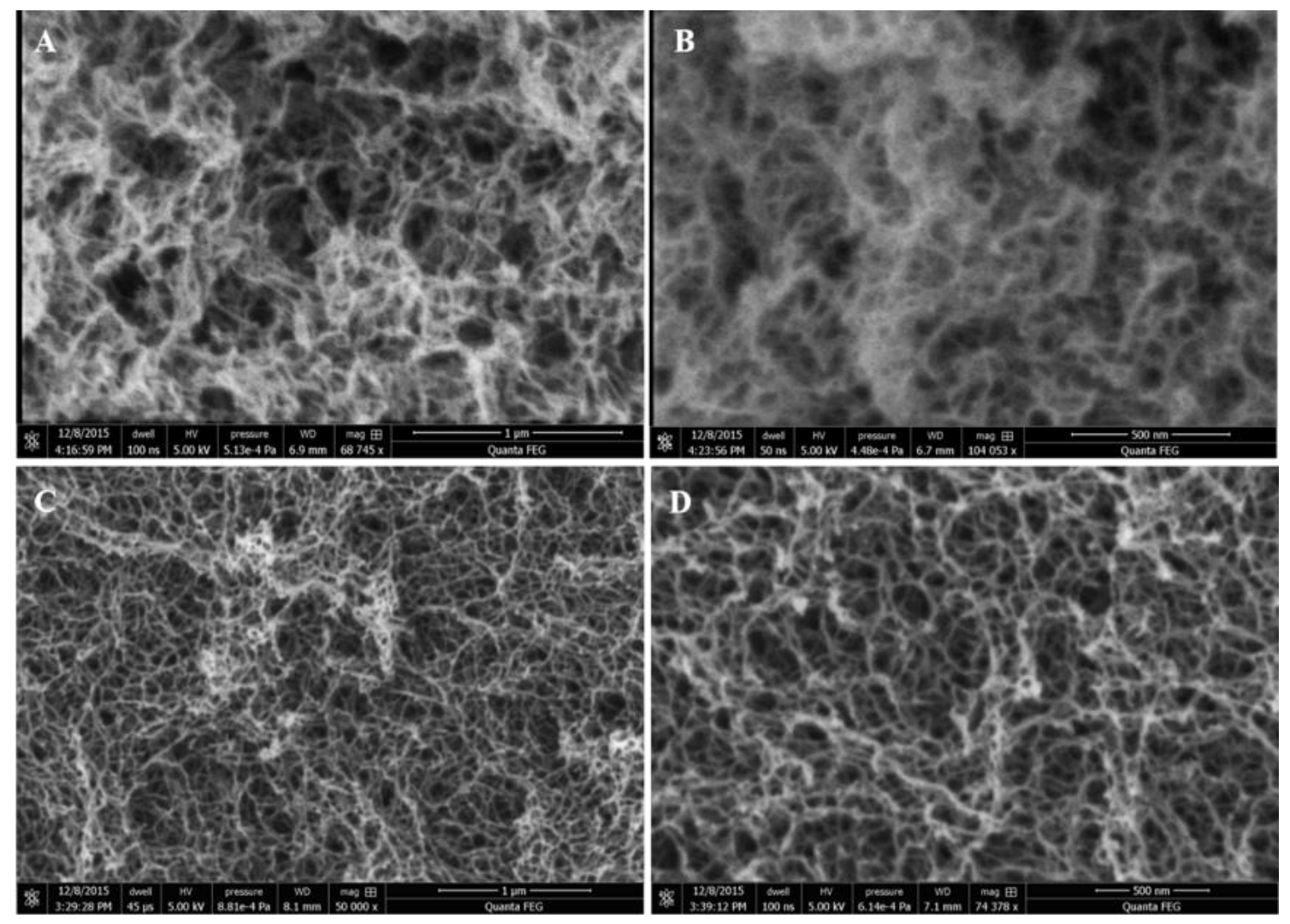


FIGURE 2
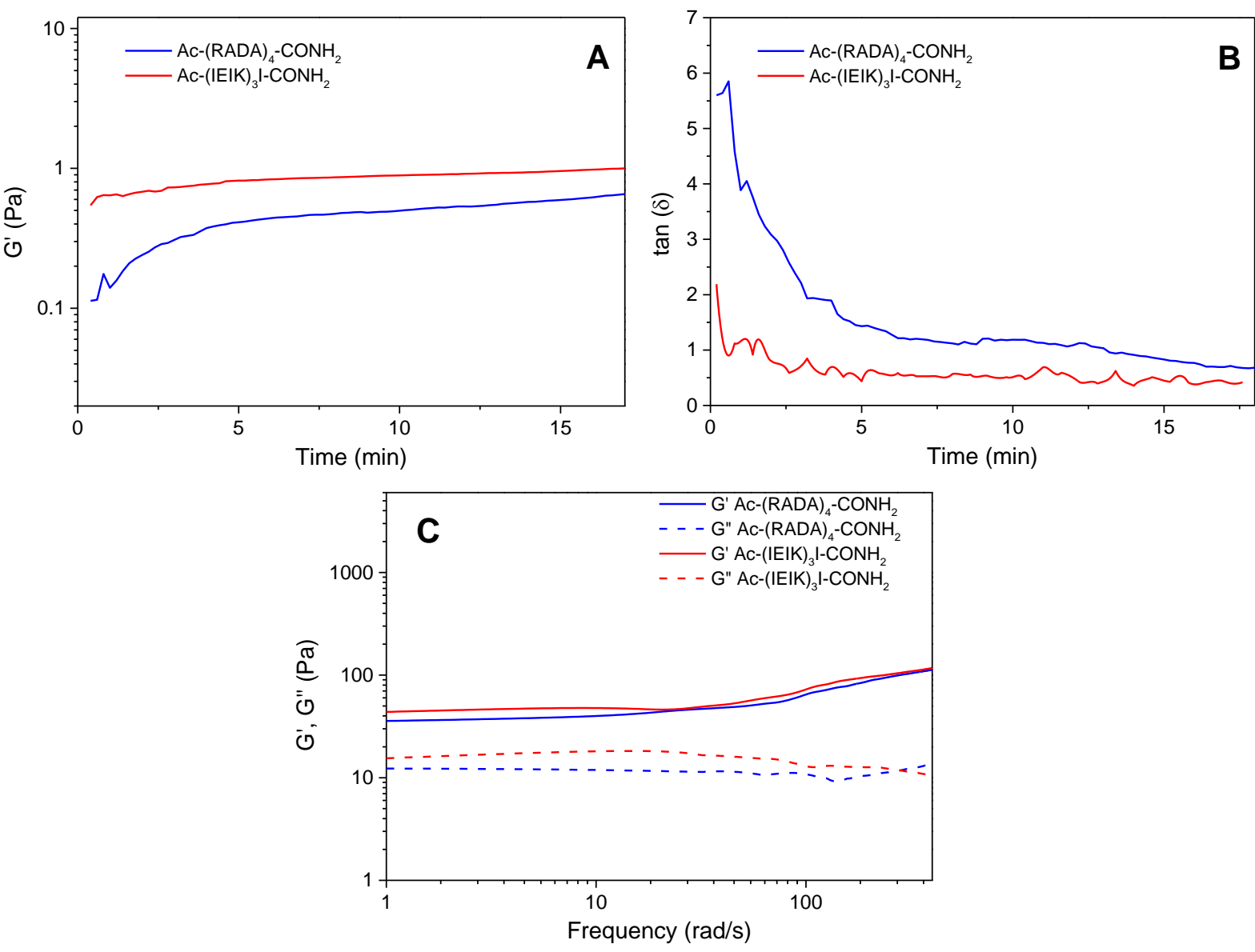
FIGURE 3
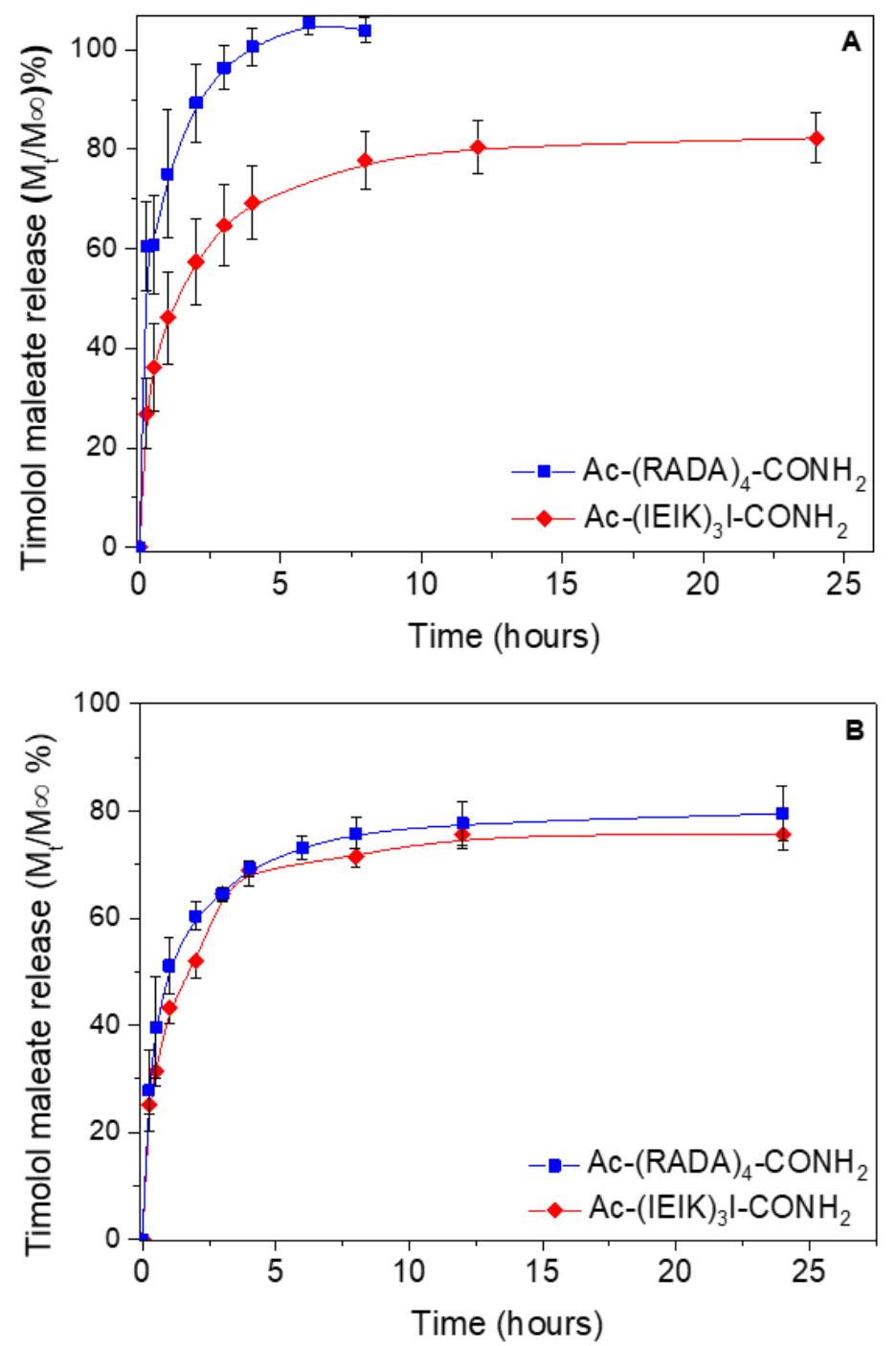


\section{FIGURE 4}

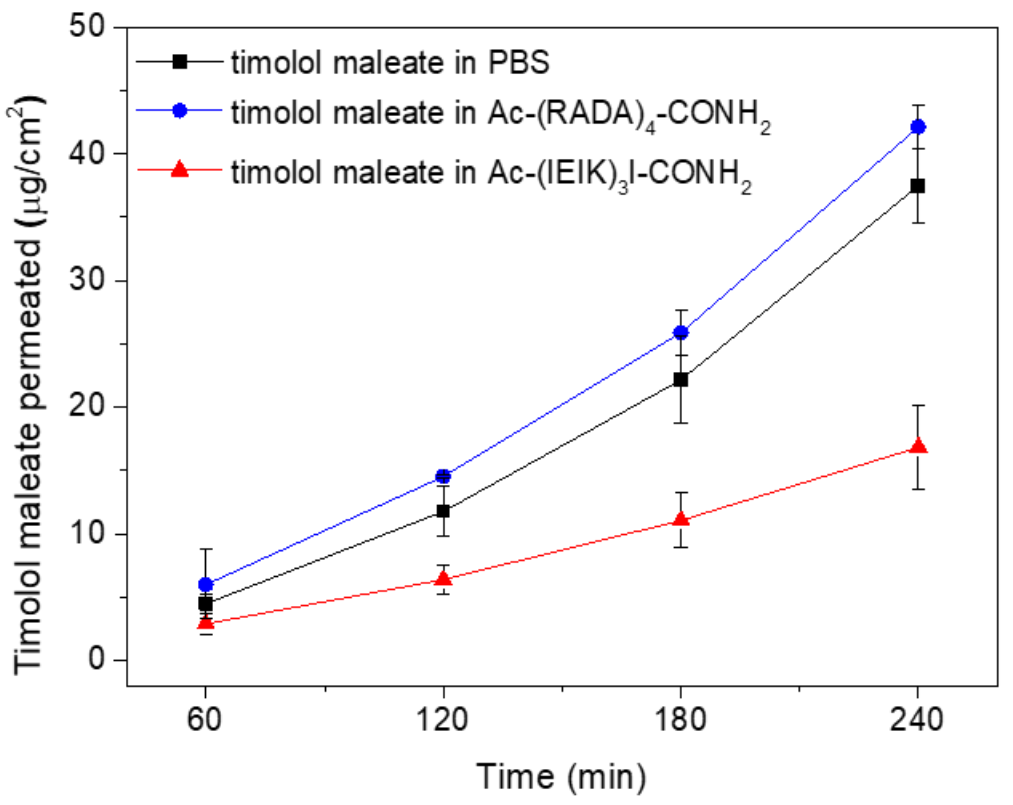




\section{FIGURE 5}

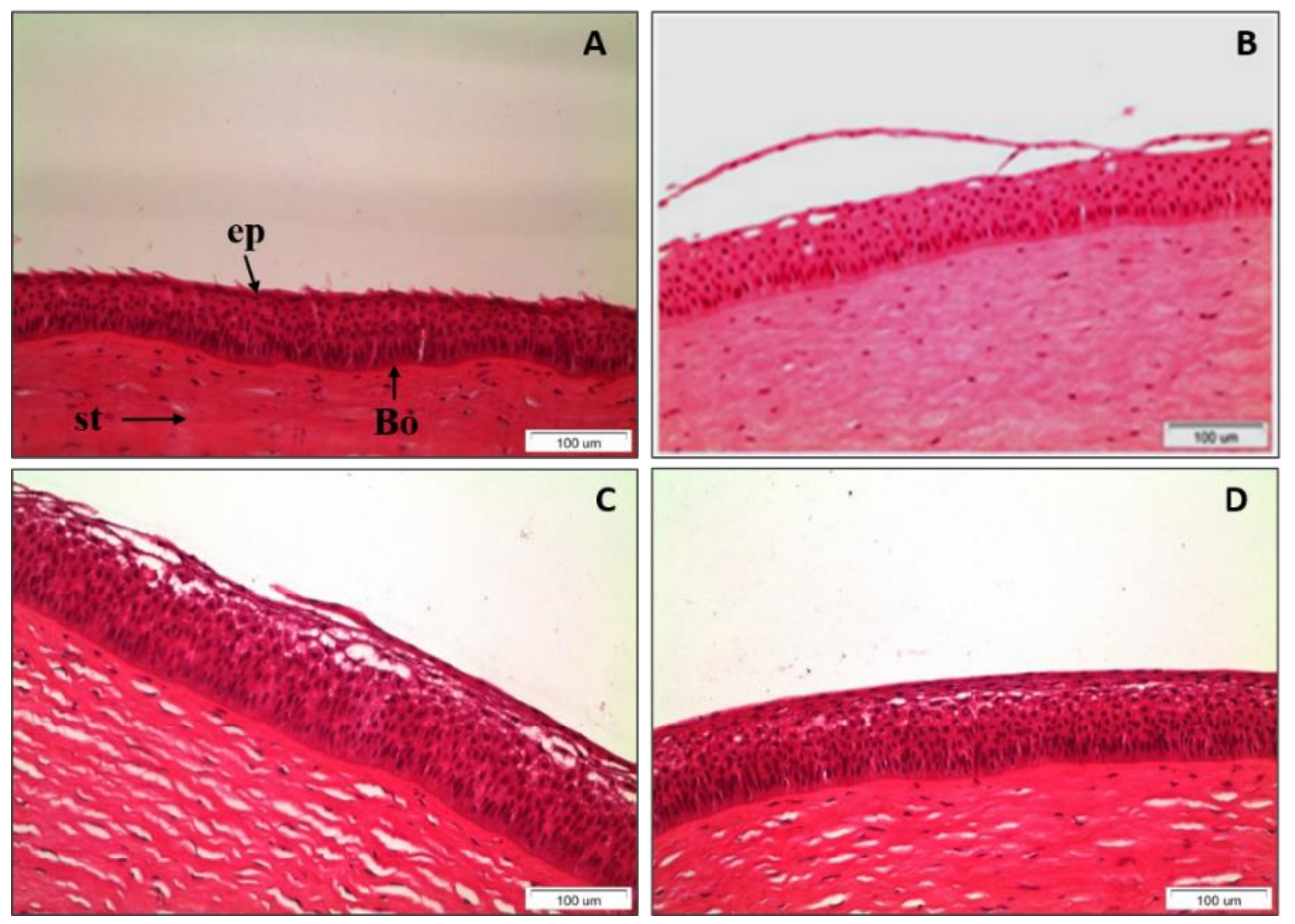




\section{FIGURE 6}

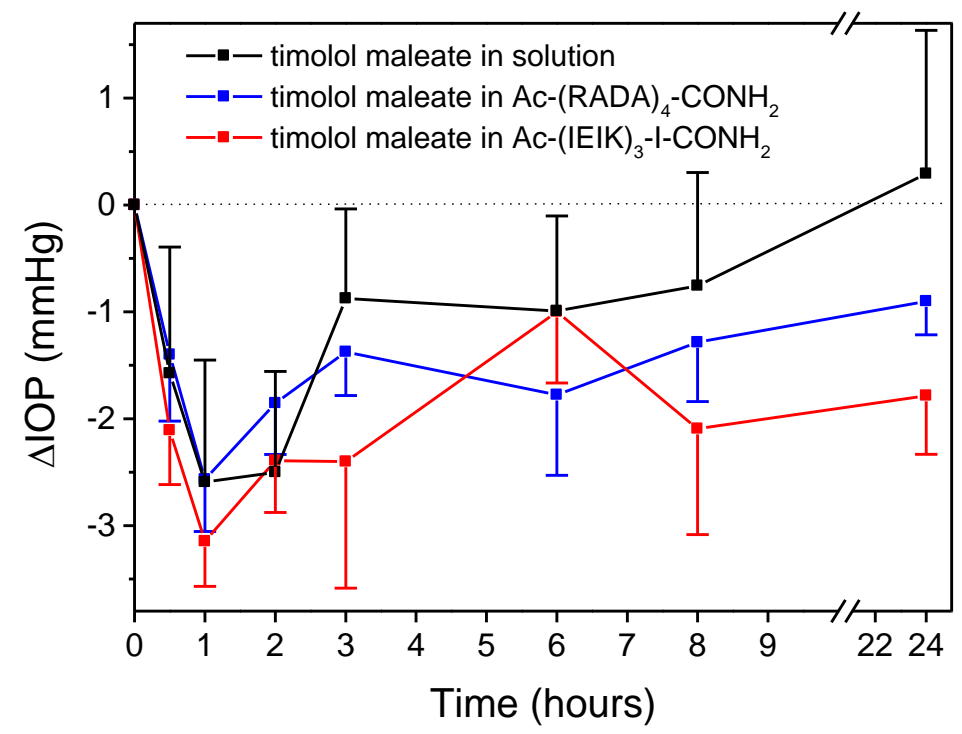


FIGURE 7

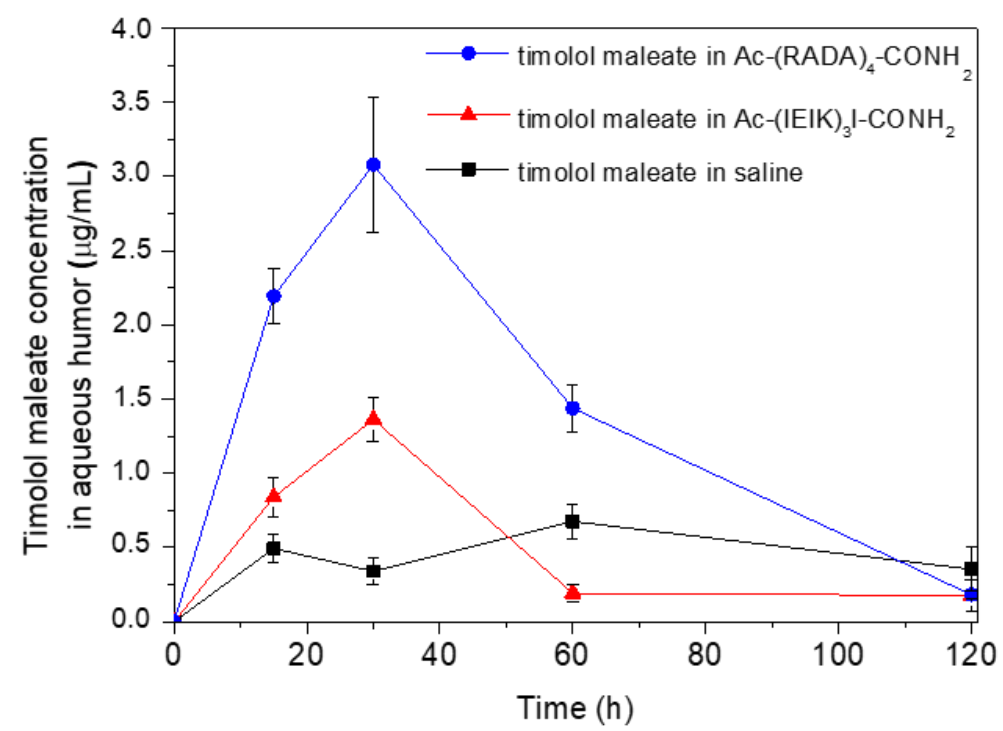




\section{FIGURE 8}

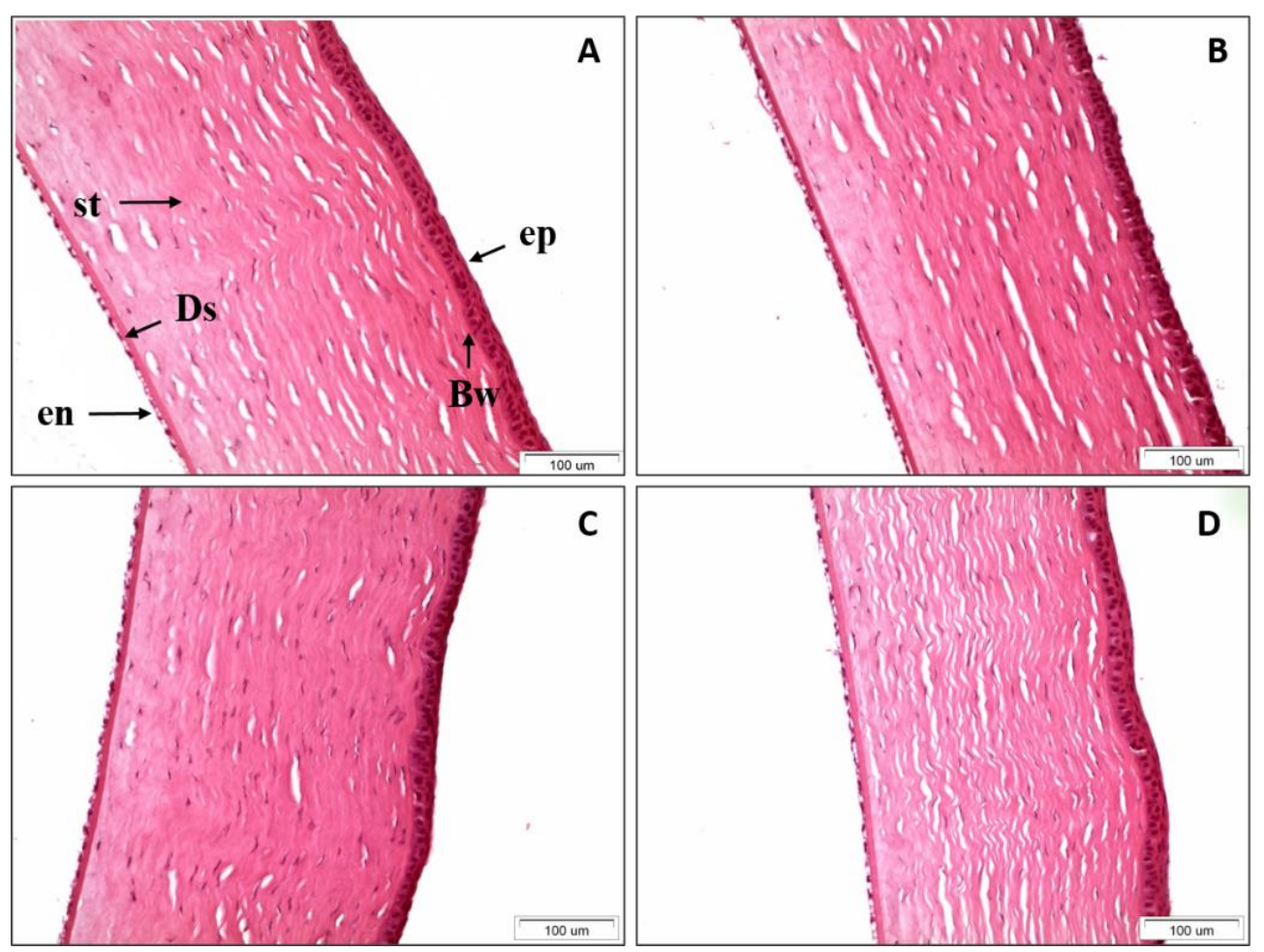




\section{Table of Contents graphic}

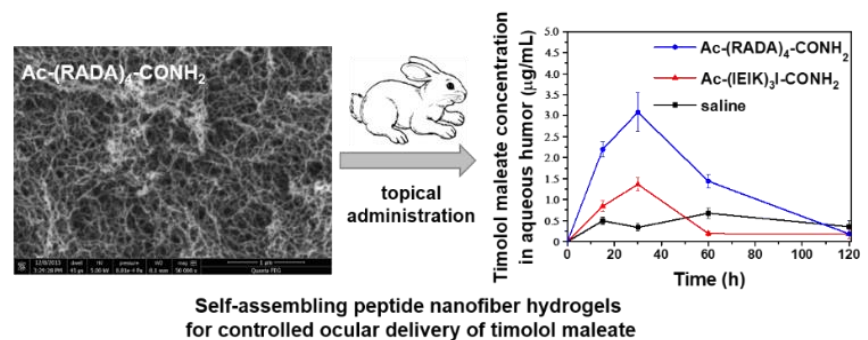

for controlled ocular deliver

\section{Self-assembling peptide nanofiber hydrogels for controlled ocular delivery of}

\section{timolol maleate}

Christina Karavasili, Anastasia Komnenou, Orestis L. Katsamenis, Glykeria Charalampidou, Evangelia Kofidou, Dimitrios Andreadis, Sotirios Koutsopoulos, Dimitrios G. Fatouros 